\title{
Can biochemical pregnancy be determined 5 days after frozen- thawed embryo transfer?
}

\author{
Isaac M Yadid ${ }^{1}$, Thelma S Criscuolo ${ }^{1,2}$, Jéssica F Santos ${ }^{1,3}$, Luiz A Giordano ${ }^{1,4}$ \\ ${ }^{1}$ Clínica Primordia Medicina Reprodutiva, Rio de Janeiro, RJ, Brazil \\ ${ }^{2}$ Instituto de Biofísica Carlos Chagas Filho, Universidade Federal do Rio de Janeiro (UFRJ), Rio de Janeiro, RJ, \\ Brazil \\ ${ }^{3}$ Departamento de Biologia Geral, Laboratório de Genética Humana e Mutagênese - Universidade Federal da \\ Bahia (UFBA), Salvador, BA, Brazil \\ ${ }^{4}$ Hospital Universitário Gaffrée e Guinle, Universidade Federal do Estado do Rio de Janeiro (UNIRIO), Rio de \\ Janeiro, RJ, Brazil
}

\begin{abstract}
Objective: To study the predictive value of serum $\beta$-hCG on day 5 after frozen-thawed embryo transfer (FET) to predict pregnancy outcomes and to establish cut-off values for very early biochemical pregnancy diagnosis.

Methods: This retrospective cohort study was performed at a private reproductive medicine centre and we reviewed the medical records of women who underwent FET cycles from January 2018 to June 2019. A total of 116 evaluated cycles had serum $\beta$-hCG levels measured on days 5 and 10 after FET. The predictive value of serum $\beta$-hCG levels measured on day 5 after FET was investigated for very early biochemical pregnancy diagnosis.

Results: The standard biochemical pregnancy diagnosis was defined as a $\beta-\mathrm{hCG} \geq 25 \mathrm{IU} / \mathrm{L}$ on day 10 after FET. We then generated a receiver operating characteristic curve, and the cut-off value of $\beta$-hCG on day 5 for predicting biochemical pregnancies was $4.0 \mathrm{IU} / \mathrm{L}$, with $93.4 \%$ sensitivity and $92.7 \%$ specificity (AUC, $0.960 ; 95 \%$ confidence interval, 0.923-0.997).

Conclusions: Values for $\beta$-hCG at day 5 after FET $\geq 4$.0IU/L are accurate for the diagnosis of biochemical pregnancy. The use of very early biochemical pregnancy diagnosis in clinical practice enables earlier management, patient counselling, and appropriate follow-up.
\end{abstract}

Keywords: $\beta$-hCG, biochemical pregnancy test, frozenthawed embryo transfer

\section{INTRODUCTION}

Human chorionic gonadotropin (hCG) is the first hormonal signal of the presence of an embryo. Blastocysts express hCG even before implantation, and its production by the syncytiotrophoblast increases further after implantation, until peak hCG production between the $10^{\text {th }}$ and $11^{\text {th }}$ week of gestation (Makrigiannakis et al., 2017). The detection of hCG has been used to detect pregnancy since the 1920s. Knowledge concerning hCG physiology and the evolution of bioassays enabled the introduction of radioimmunoassay and commercial hCG tests at the end of the 1960 s. In 1973, a radioimmunoassay that specifically detected the hCG $\beta$ subunit ( $\beta$-hCG) was introduced and led to more reliable pregnancy tests. Immunoassays can detect hCG tracers through sensitive antibody enzyme labelling and high sensitivity fluorometric and chemiluminescent methods (Cole, 2009). $\beta$-hCG levels can be measured in the maternal blood as early as 10 days after fertilization, and pregnancy can be detected soon after missing menses (Makrigiannakis et al., 2017).

In in vitro fertilization (IVF) cycles, embryos are usually transferred to the uterus on days 3 to 5 of development, and a single determination of maternal serum $\beta$-hCG concentration 11-12 days after embryo transfer is a reliable indicator of pregnancy that is generally used by reproductive medicine specialists (Bjercke et al., 1999). A number of studies have shown that the $\beta$-hCG levels after IVF cycles can be used to predict a viable pregnancy and the results can be interpreted using different cut-off values depending on the situation (Heiner et al., 1992; Schmidt et al., 1994; Fridström et al., 1995; Glatstein et al., 1995; Guth et al., 1995; Qasim et al., 1996; Chen et al., 1997; Bjercke et al., 1999; Homan et al., 2000; Sugantha et al., 2000; Papageorgiou et al., 2001; Poikkeus et al., 2002; Urbancsek et al., 2002; Carmona et al., 2003; Lambers et al., 2006; Stone et al., 2006; Porat et al., 2007; Delbaere et al., 2008; Shamonki et al., 2009; Basirat \& Bijani, 2010; Chi et al., 2010; Kathiresan et al., 2011; Lawler et al., 2011; Reljič et al., 2013; Asvold et al., 2014; Sung et al., 2016; Dypvik et al., 2018).

Under physiological conditions, a positive pregnancy is generally indicated when $\beta$-hCG levels reach $25 \mathrm{mIU} /$ $\mathrm{ml} 10$ days after conception and increase exponentially thereafter, doubling roughly every 2-3 days for the first 4 weeks of pregnancy. In contrast, levels below $5 \mathrm{mIU} / \mathrm{mL}$ exclude pregnancy, and slower than expected increases in $\beta$-hCG indicate abnormal outcomes (Fan et al., 2017). This pattern is similar in both natural and IVF conceptions. Therefore, $\beta$-hCG levels are traditionally measured after missing menses in natural conceptions or from 10 days after embryo transfer in IVF cycles, which correspond to around 15 days after conception in both situations (Lenton et al., 1991). The urine test can be positive about 12 to 14 days after conception. Thus, once the patients go through the urine test, we believe that the greater sensitivity of the blood test would be capable of an earlier diagnosis.

There is no study showing the $\beta$-hCG measurement before 10 days after embryo transfer in IVF cycles for biochemical pregnancy diagnosis. However, in clinical practice there are a number of patients who run urine pregnancy tests sold over-the-counter in order to obtain earlier answer about the success of their treatment and obtain positive results. The high sensitivity of commercial tests available today, especially serum measurements, enables serum $\beta$-hCG detection levels as low as $0.1 \mathrm{mIU} / \mathrm{mL}$. Based on this, we hypothesized that serum $\beta$-hCG levels could be measured as soon as 5 days after embryo transfer in order to predict pregnancy following IVF cycles. Thus, the aim of 
this study was to evaluate the feasibility of serum $\beta$-hCG measurement on day 5 after embryo transfer to predict pregnancy outcomes in frozen-thawed IVF cycles, and establish cut-off values for that.

\section{METHODS}

\section{Study population}

This was a retrospective cohort study that included the medical records of women who underwent frozen-thawed embryo transfer (FET) cycles from January 2018 to June 2019 at a private reproductive medicine center in Brazil. All procedures performed in the patients included were part of the routine care in our center, and we obtained written informed consent from all patients before treatment. The patients consented to the diagnostic and treatment procedures, and to the use of retrospective data for scientific publications, respecting anonymity. Consequently, the study was exempt from approval by the Institutional Review Board.

We reviewed the medical records of the patients, and inclusion criteria were FET cycles and determination of serum $\beta$-hCG measurements on days 5 and 10 after embryo transfers. Among 698 eligible FET cycles, 132 patients had determination of serum $\beta$-hCG on days 5 and 10 . From those we excluded 16 cycles in which the embryos were biopsied for preimplantation genetic testing for aneuploidies. As a result, the study samples comprised 116 FET cycles.

\section{Treatment protocol}

All the patients underwent a short protocol for ovarian stimulation according to routine and standard protocols. Briefly, pituitary blockage was performed with a gonadotropin-releasing hormone $(\mathrm{GnRH})$ antagonist, and we achieved ovarian stimulation using recombinant FSH associated or not to recombinant LH or human menopausal gonadotropin (HMG), with flexible dose adjustments as necessary. When at least two leading follicles reached $18 \mathrm{~mm}$, final oocyte maturation was triggered by a GnRH agonist or hCG, and oocyte pickup was performed 36-38 hours later. We fertilized the oocytes through intracytoplasmic sperm injection, and evaluated the embryos by morphological criteria; blastocysts were considered of top quality when they were expanded (grade 4 or 5 ), and both the inner cell mass and the trophectoderm were classified as A (Gardner et al., 2000). Viable embryos were either transferred or cryopreserved for further frozen-thawed embryo transfer.

For the frozen-thawed embryo transfers, hormone replacement cycles were accomplished with oral estradiol valerate (Primogyna, $2 \mathrm{mg}$ every 8 hours) or transdermal gel (Oestrogel, 2 pumps every 12 hours), starting on the second or third day of the menstrual cycle. When the endometrium reached at least $7 \mathrm{~mm}$, micronized progesterone was administered orally (Utrogestan, $200 \mathrm{mg}$ every 12 hours), and vaginal micronized progesterone (Crinone $8 \%$, one application a day) was added until at least the point of the pregnancy test. For the frozen-thawed embryo transfers, embryos were warmed, evaluated for survival and morphology, and transferred at day 5 or 6 of development. One to three blastocysts were transferred according to the patient age following the Brazilian recommendation (CFM, 2017).

\section{Serum hormone measurements}

The $\beta$-hCG Serum concentrations were measured on days 5 and 10 after blastocyst transfers in the peripheral blood at tertiary laboratories and results were expressed in IU/L. Women were oriented to collect blood on day 5 afterward at least 120 hours after FET for $\beta$-hCG detection. We collected the data from medical records, and we used the $\beta$-hCG on day 10 after blastocyst transfer as the gold standard for pregnancy diagnosis, in which values $\geq 25 \mathrm{IU} / \mathrm{L}$ were considered positive biochemical pregnancies. We also measured the serum estradiol (E2) and progesterone (P4) concentrations.

\section{Data analysis}

All statistical analyses were conducted using the IBM SPSS Statistics Version 21.0 (IBM Corp., USA). Means and standard deviations were calculated for continuous variables, and Student's t-test was used for comparisons. We used the Chi-square test or the Fisher's exact test to compare the frequencies and proportions, as appropriate. Receiver operator characteristic (ROC) curves were constructed to determine the sensitivity and specificity for biochemical pregnancy prediction based on the $\beta$-hCG levels on day 5 after blastocyst transfer, and to determine the cut-off value that best discriminated between positive and negative biochemical pregnancies. Statistical significance was set at $p \leq 0.05$.

\section{RESULTS}

The included patients were $37.8 \pm 4.4$ years old. There was a single embryo transfer for 32 women $(27.6 \%)$, two embryos were transferred for 78 women $(67.2 \%)$, and six patients had three embryos transferred $(5.2 \%)$. The biochemical pregnancy rate based on the $\beta$-hCG levels on day 10 was $52.6 \%$. Table 1 demonstrates the general characteristics of the total study population, and those with negative and positive biochemical pregnancy according to $\beta$-hCG levels on day 10 .

Among the 61 patients who had positive $\beta$-hCG levels on day 10 ( $\geq 25 \mathrm{IU} / \mathrm{L}$ ), 60 also had positive $\beta$-hCG levels on day 5 , varying from 2.2 to $75.5 \mathrm{IU} / \mathrm{L}$. Considering $\beta$-hCG levels on day $10 \geq 25 \mathrm{IU} / \mathrm{L}$ as standard, a ROC curve analysis showed that $4.0 \mathrm{IU} / \mathrm{L}$ is the cut-off value of $\beta$-hCG on day 5 for biochemical pregnancy diagnosis. That analysis had $93.4 \%$ sensitivity and $92.7 \%$ specificity (AUC, $0.960 ; 95 \%$ confidence interval, 0.923-0.997) (Figure 1 ).

If we consider the $\beta$-hCG concentration on day of $5 \geq$ $4.0 \mathrm{IU} / \mathrm{L}$ to diagnose biochemical pregnancy, the concordance between positive tests based on days 5 ( $\beta$-hCG $\geq$ $4.0 \mathrm{IU} / \mathrm{L}$ ) and $10(\beta-\mathrm{hCG} \geq 25.0 \mathrm{IU} / \mathrm{L}$ ) was high (measure of agreement Kappa, $0.86 ; p<0.001)$. Moreover, the positive predictive value (PPV) was $93.4 \%$, and the negative predictive value (NPV) was $92.7 \%$. Four women had negative tests on day $5(\beta-\mathrm{hCG}<4.0 \mathrm{IU} / \mathrm{L})$, and were positive in the $\beta$-hCG day 10 (false negative outcomes), while the remaining four women had a positive test on day 5 ( $\beta$-hCG $\geq 4.0 \mathrm{IU} / \mathrm{L}$ ) that was not confirmed in the $\beta$-hCG test on day 10 (false positive outcome).

In one patient with positive biochemical pregnancy ( $\beta$-hCG concentration on day $10 \geq 25.0 \mathrm{IU} / \mathrm{L}$ ) the gestational sac was not seen upon the ultrasound. That patient also had $\beta$-hCG concentration on day $5 \geq 4.0 \mathrm{IU} / \mathrm{L}$. The clinical pregnancy rate, defined by the visualization of a gestational sac and the presence of a heartbeat, was $48.3 \%$ and the live birth rate was $37.9 \%$. The multiple pregnancy rate was $20.0 \%$.

\section{DISCUSSION}

Generally, a single quantitative measurement of $\beta$-hCG levels, 10-12 days after embryo transfer in IVF cycles is an excellent method to diagnose pregnancy (Poikkeus et al., 2002). Several studies have evaluated $\beta$-hCG concentration as a predictor of pregnancy outcomes after IVF. However, the $\beta$-hCG concentrations are generally measured at least 10 days (Kathiresan et al., 2011), 11 or 12 days (Qasim et al., 1996), 12 days (Poikkeus et al., 2002; Lawler et al., 2011; Asvold et al., 2014; Dypvik et al., 2018; Tanbo et 


\begin{tabular}{|l|c|c|c|c|}
\hline Table 1. Patient characteristics, cycle parameters, and serum $\beta$-hCG levels (mean \pm SD). \\
\hline & $\begin{array}{c}\text { Total of } \\
\text { patients } \\
\text { (mean } \pm \text { SD) }\end{array}$ & $\begin{array}{c}\text { Negative } \\
\text { biochemical } \\
\text { pregnancy } \\
\text { (mean } \pm \text { SD) }\end{array}$ & $\begin{array}{c}\text { Positive } \\
\text { biochemical } \\
\text { pregnancy } \\
\text { (mean } \pm \text { SD) }\end{array}$ & p \\
\hline N & 116 & 55 & $38.0 \pm 4.2$ & 0.656 \\
\hline Age (years) & $37.8 \pm 4.4$ & $37.6 \pm 4.6$ & $1.9 \pm 0.5$ & 0.050 \\
\hline No. of embryos transferred & $1.8 \pm 0.5$ & $1.7 \pm 0.5$ & $21.0 \pm 16.3$ & $<0.001$ \\
\hline$\beta$-hCG day $5(\mathrm{IU} / \mathrm{L})$ & $11.8 \pm 15.4$ & $1.6 \pm 2.9$ & $213.5 \pm 119.4$ & 0.109 \\
\hline E2 day $5(\mathrm{pg} / \mathrm{mL})$ & $198.6 \pm 109.1$ & $180.9 \pm 93.5$ & $51.8 \pm 92.6$ & 0.639 \\
\hline P4 day $5(\mathrm{ng} / \mathrm{mL})$ & $56.0 \pm 100.5$ & $60.8 \pm 109.6$ & $330.0 \pm 218.9$ & $<0.001$ \\
\hline$\beta$-hCG day $10(\mathrm{IU} / \mathrm{L})$ & $174.3 \pm 228.3$ & $1.7 \pm 4.0$ & $266.3 \pm 189.7$ & 0.004 \\
\hline E2 day $10(\mathrm{pg} / \mathrm{mL})$ & $224.8 \pm 161.8$ & $175.2 \pm 101.9$ & $54.5 \pm 107.8$ & 0.939 \\
\hline P4 day $10(\mathrm{ng} / \mathrm{mL})$ & $53.7 \pm 107.3$ & $52.8 \pm 107.9$ & 2 \\
\hline
\end{tabular}

Total patient data were divided into two groups according to biochemical pregnancy outcome ( $\beta$-hCG levels on day $10 \geq 25$ IU/L).*Student t-test comparing means between subgroups of negative and positive biochemical pregnancy based on $\beta$-hCG levels on day 10 .

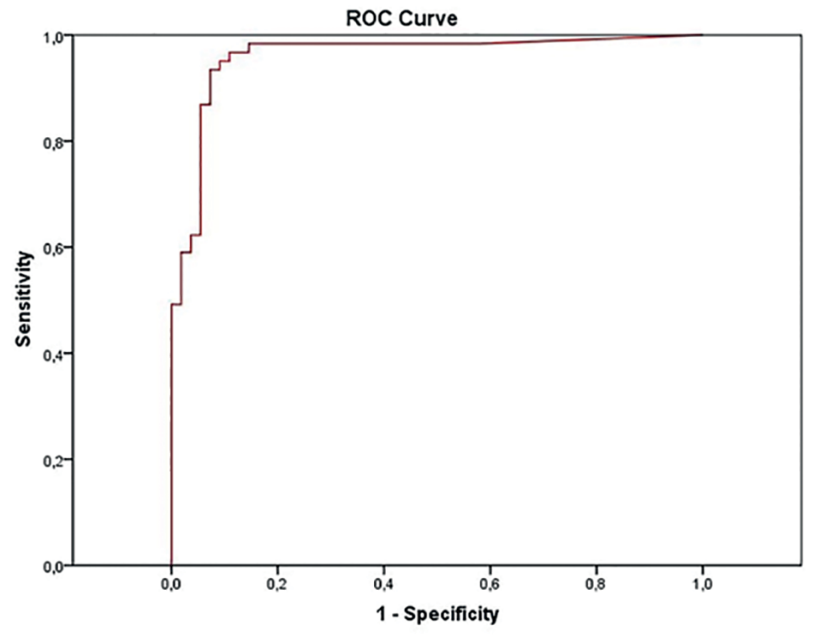

Figure 1. Receiver operating characteristic curve for predicting biochemical pregnancy from serum $\beta$-hCG concentration on day 5 after blastocyst transfer in frozenthawed cycles. The $y$-axis represents the sensitivity and the $\mathrm{x}$-axis 1 -especificity.

al., 2018), 13 days (Porat et al., 2007; Reljič et al., 2013), 12 and 13 days (Carmona et al., 2003), 12 and 14 days (Sung et al., 2016), 12 and 24 days (Stone et al., 2006), 14 and 21 days (Sugantha et al., 2000; Chi et al., 2010), and 15 to 35 days after embryo transfer (Delbaere et al., 2008). Our study aimed to evaluate whether the serum $\beta$-hCG values on day 5 after embryo transfer can be used to diagnose biochemical pregnancy after frozen-thawed IVF cycles, as well as to determine the appropriate cutoff values. We found that a single measurement of $\beta$-hCG concentration on day 5 after embryo transfer $\geq 4.0 \mathrm{IU} / \mathrm{L}$ can be used as an early diagnostic marker of biochemical pregnancy, with high sensitivity and specificity.

Although hCG can be detected as early as 8-11 days after ovulation, shortly after implantation, in IVF cycles the hCG is commonly used during ovarian stimulation, as well as to trigger final oocyte maturation. Indeed, exogenous hCG leads to false positive tests if the $\beta$-hCG concentration is measured before the clearance. On the other hand, pharmacodynamics studies have shown that the complete clearance of exogenous hCG occurs 8 to 12 days after the last application, and that the $\beta$-hCG measured in serum on days 12-13 after embryo transfer is of trophoblastic origin (Liu et al., 1988). This rationale has been used to justify the $\beta$-hCG measurements only after 10 days of embryo transfer, in order to assure complete clearance of exogenous hCG administered during ovulation induction and/or trigger in fresh transfer cycles.

Our study was careful to evaluate only frozen-thawed embryo transfer cycles, in which the patients underwent hormone replacement with estradiol and progesterone, and then there was no influence of exogenous hCG. Hence, it was possible to determine the $\beta$-hCG level as early as 5 days after embryo transfer to predict pregnancy with no influence from ovarian stimulation or trigger drugs. In addition, the high sensitivity of the biochemical tests enabled accurate determination of $\beta$-hCG concentrations as low as $1 \mathrm{IU} / \mathrm{L}$, which renders a cut-off of $4 \mathrm{IU} / L$, as defined in our study.

With regards to defining the accuracy of the $\beta$-hCG levels on day 5 to diagnose pregnancy, a short definition of metrics used in this study can be appropriate. Sensitivity and specificity are concerned with the accuracy of a screening test relative to a reference standard, while PPV and NPV indicate the effectiveness of a test for categorizing people by the presence or absence of a target condition (Trevethan, 2017). Despite the outcomes showing that all metrics (sensitivity, specificity, PPV, and NPV) were very similar and all over $90 \%$, the use of PPV and NPV to determine the effectiveness of the use of $\beta$-hCG 5 days after frozen embryo transfer to pregnancy diagnosis seems to be more appropriate. We found that the probability that people with a positive screening test indeed have the condition of interest (i.e., identifying true positives; here, the positive biochemical test on day 5) was $93.4 \%$ (PPV). In addition, the probability of correctly identifying people who do not have the condition (i.e., identifying true negatives) was $92.7 \%$ (PNV), showing the accuracy of the measurement of $\beta$-hCG on day 5 to accurately diagnose pregnancy.

A limitation of our study is the possible influence of multiple pregnancies. Twin pregnancies result in higher $\beta$-hCG levels, which could be a bias in the analysis as 12 from 60 positive pregnancies $(20.0 \%)$ were twins. However, we performed a supplementary analysis excluding multiple pregnancies and obtained similar outcomes of 
$\beta$-hCG concentration sensitivity and specificity on day $5 \geq$ $4.0 \mathrm{IU} / \mathrm{L}$ to be used as early diagnostic of pregnancy (data not shown). However, the mean $\beta$-hCG value on day 5 for those 12 patients was $28.1 \mathrm{IU} / \mathrm{L}$, which is much higher than the cutoff established to predict pregnancy in general (4.0 IU/L). This suggests that the $\beta$-hCG values on day 5 follow the same pattern of those practiced in the routine of pregnancy diagnosis ( $\beta$-hCG measured on day 10 ), when higher values can also indicate multiples pregnancies.

Another necessary consideration relies on the supposed false-positive and false-negative tests. In our study, four women who had positive $\beta$-hCG on day 5 were negative for $\beta$-hCG on day $10(3.4 \%)$, which should be considered as a false positive outcome. In this case, we can argue that those women had a real positive test on day 5 , diagnosing a biochemical pregnancy that did not progress, as there is no other possible origin of $\beta$-hCG than the embryo. In contrast, the four women who had negative $\beta$-hCG concentrations on day 5 and were positive for $\beta$-hCG concentration on day $10(3.4 \%)$, were considered as false negatives. The last situation can be considered a genuine false negative outcome, where the levels of $\beta$-hCG were lower than the established cut-off for pregnancy diagnosis.

However, it is important to highlight that this is not a prospective controlled study, the data were obtained retrospectively and represent a real-world IVF practice. Thus, some possible bias should be addressed. The very early biochemical pregnancy test, 5 days after FET, can be influenced by the blood collection time, and the patients were instructed that it should be performed at least 120 hours after embryo transfer. However, the blood was collected in a tertiary laboratory, and the time between embryo transfer and blood collection was not strictly controlled. Moreover, variations in time of implantation can also represent a bias. The embryos were transferred when the blastocyst stage was attained, on days 5 or 6 of development according to routine, which can lead to different implantation times and consequently affect the early levels of maternal $\beta$-hCG. Hence, those are possible bias of our study and despite the low incidence of false negative tests (3.4\%), those factors can be associated to their occurrence.

Very early pregnancy diagnosis after IVF offers a number of advantages. IVF patients are physically and psychologically demanding, and their anxiety levels vary during the treatment. The period preceding the pregnancy test is one of the periods with a high level of anxiety (Harata et al., 2012). We intend to continue this study and evaluate how the very early pregnancy test ( $\beta$-hCG performed on day 5 after embryo transfer) could affect the patient's anxiety level. Another point is the luteal phase support after frozen-thawed embryo transfer, in which progesterone supplementation is routinely administered until at least the day of the pregnancy test, and prolonged until 8 weeks if pregnancy is achieved (Tomic et al., 2019). Once pregnancy can be diagnosed earlier, luteal support with progesterone can be managed accordingly.

It is important to highlight that the findings of our study are reliable for FET, and despite the possible bias inherent to a retrospective study, it represents the clinical practice. Our findings showed the very early diagnosis of pregnancy is feasible and accurate by measuring the $\beta$-hCG levels as early as 5 days after FET. On the other hand, once the complete clearance of exogenous hCG occurs 8 to 12 days after the last application (Liu et al., 1988), the use of $\beta$-hCG levels as early as 5 days after embryo transfer using the parameters stablished here, is not applicable for fresh transfers when hCG is used in the stimulation or trigger protocol. Also, it remains unknown whether the $\beta$-hCG levels after fresh or frozen-thawed embryo transfer cycles are similar (Reljič et al., 2013; Sung et al., 2016), and the generalization of our findings for fresh transfers must be validated.

To the best of our knowledge, this is the first study to analyze the predictive value of serum $\beta$-hCG concentrations as early as 5 days after frozen-thawed embryo transfer cycles to pregnancy diagnosis. Our data demonstrate that a cut-off value for $\beta$-hCG on day 5 after embryo transfer $\geq 4.0 \mathrm{IU} / \mathrm{L}$ is accurate for the diagnosis of biochemical pregnancy, and its use in clinical practice enables earlier management, counselling of patients, and appropriate follow-up.

\section{ACKNOWLEDGEMENTS}

The authors gratefully acknowledge the contributions of the team from Primordia, Rio de Janeiro, Brazil, for their excellent support with patients, procedures, and data collection. They also acknowledge Dr. Tatiana CS Bonetti for data analysis and manuscript writing assistance, and EDITAGE for the English.

\section{CONFLICT OF INTERESTS}

The authors have no disclose of any commercial or financial interests, or any other conflict of interest associated with the publication of this paper.

\section{Corresponding author:}

Isaac M. Yadid, MD

Clínica Primordia - Medicina Reprodutiva

Rio de Janeiro, RJ, Brazil

E-mail: isaac@clinicaprimordia.com.br

\section{REFERENCES}

Asvold BO, Vatten LJ, Tanbo TG, Eskild A. Concentrations of human chorionic gonadotrophin in very early pregnancy and subsequent pre-eclampsia: a cohort study. Hum Reprod. 2014;29:1153-60. PMID: 24722241 DOI: 10.1093/ humrep/deu068

Basirat Z, Bijani A. Serum beta human chorionic gonadotropin levels at 16 days following embryo transfer in intra cytoplasmic sperm injection cycles to predict pregnancy outcome. Saudi Med J. 2010;31:1015-20. PMID: 20844814

Bjercke S, Tanbo T, Dale PO, Mørkrid L, Abyholm T. Human chorionic gonadotrophin concentrations in early pregnancy after in-vitro fertilization. Hum Reprod. 1999;14:1642-6. PMID: 10357992 DOI: 10.1093/humrep/14.6.1642

Carmona F, Balasch J, Creus $M$, Fábregues F, Casamitjana R, Cívico S, Vidal E, Calafell JM, Moreno V, Vanrell JA. Early hormonal markers of pregnancy outcome after in vitro fertilization and embryo transfer. J Assist Reprod Genet. 2003;20:521-6. PMID: 15035553 DOI: 10.1023/B:JARG.0000013654.85531.ac

CFM - Conselho Federal de Medicina. Resolução No 2.168. Normas éticas para a utilização das técnicas de reprodução assistida. Brasília, DF: CFM; 2017. Available at: https:// www.in.gov.br/materia/-/asset_publisher/Kujrw0TZC2Mb/ content/id/19405123/do1-2017-11-10-resolucao-n-2168-de-21-de-setembro-de-2017-19405026

Chen CD, Ho HN, Wu MY, Chao KH, Chen SU, Yang YS. Paired human chorionic gonadotrophin determinations for the prediction of pregnancy outcome in assisted reproduction. Hum Reprod. 1997;12:2538-41. PMID: 9436702 DOI: $10.1093 /$ humrep/12.11.2538 
Chi $\mathrm{H}$, Qiao J, Li H, Liu P, Ma C. Double measurements of serum HCG concentration and its ratio may predict IVF outcome. Reprod Biomed Online. 2010;20:504-9. PMID: 20207583 DOI: 10.1016/j.rbmo.2010.01.005

Cole LA. New discoveries on the biology and detection of human chorionic gonadotropin. Reprod Biol Endocrinol. 2009;7:8. PMID: 19171054 DOI: 10.1186/1477-7827-7-8

Delbaere I, Vansteelandt S, Gerris J, De Sutter P, De Bacquer $\mathrm{D}$, Temmerman $\mathrm{M}$. Human chorionic gonadotropin levels in early IVF/ICSI pregnancies are higher in singletons after single embryo transfer compared with singletons after double embryo transfer. Hum Reprod. 2008;23:24216. PMID: 18664472 DOI: 10.1093/humrep/den289

Dypvik J, Pereira AL, Tanbo TG, Eskild A. Maternal human chorionic gonadotrophin concentrations in very early pregnancy and risk of hyperemesis gravidarum: A retrospective cohort study of 4372 pregnancies after in vitro fertilization. Eur J Obstet Gynecol Reprod Biol. 2018;221:12-6. PMID: 29227846 DOI: 10.1016/j.ejogrb.2017.12.015

Fan J, Wang M, Wang C, Cao Y. Advances in human chorionic gonadotropin detection technologies: a review. Bioanalysis. 2017;9:1509-29. PMID: 29056064 DOI: 10.4155/ bio-2017-0072

Fridström M, Garoff L, Sjöblom P, Hillensjö T. Human chorionic gonadotropin patterns in early pregnancy after assisted reproduction. Acta Obstet Gynecol Scand. 1995; 74:5348. PMID: 7618452 DOI: 10.3109/00016349509024385

Gardner DK, Lane M, Stevens J, Schlenker T, Schoolcraft WB. Blastocyst score affects implantation and pregnancy outcome: towards a single blastocyst transfer. Fertil Steril. 2000;73:1155-8. PMID: 10856474 DOI: $10.1016 /$ S00150282(00)00518-5

Glatstein IZ, Hornstein MD, Kahana MJ, Jackson KV, Friedman AJ. The predictive value of discriminatory human chorionic gonadotropin levels in the diagnosis of implantation outcome in in vitro fertilization cycles. Fertil Steril. 1995;63:350-6. PMID: 7843442 DOI: 10.1016/S00150282(16)57367-1

Guth B, Hudelson J, Higbie J, Solomon B, Polley S, Thomas S, Gentry WL. Predictive value of hCG level 14 days after embryo transfer. J Assist Reprod Genet. 1995;12:13-4. PMID: 7580002 DOI: 10.1007/BF02214122

Harata $T$, Goto M, Iwase A, Kurotsuchi S, Ando $\mathrm{H}$, Osawa M, Sugita A, Kondo M, Nakamura T, Nakahara T, Takikawa S, Manabe S, Kikkawa F. Psychological stress during in vitro fertilization and embryo transfer is influenced by the patients' background and gender. Reprod Med Biol. 2012;11:143-8. PMID: 29662362 DOI: $10.1007 /$ s12522012-0124-y

Heiner JS, Kerin JF, Schmidt LL, Wu TC. Can a single, early quantitative human chorionic gonadotropin measurement in an in vitro fertilization-gamete intrafallopian transfer program predict pregnancy outcome? Fertil Steril. 1992;58:373-7. PMID: 1633905 DOI: 10.1016/S00150282(16)55232-7
Homan G, Brown S, Moran J, Homan S, Kerin J. Human chorionic gonadotropin as a predictor of outcome in assisted reproductive technology pregnancies. Fertil Steril. 2000;73:270-4. PMID: 10685527 DOI: 10.1016/S00150282(99)00512-9

Kathiresan AS, Cruz-Almeida $Y$, Barrionuevo MJ, Maxson WS, Hoffman DI, Weitzman VN, Christie DR, Manko GF, Ory SJ. Prognostic value of beta-human chorionic gonadotropin is dependent on day of embryo transfer during in vitro fertilization. Fertil Steril. 2011;96:1362-6. PMID: 22047663 DOI: $10.1016 /$ j.fertnstert.2011.09.042

Lambers MJ, van Weering HG, van't Grunewold MS, Lambalk CB, Homburg R, Schats R, Hompes PG. Optimizing hCG cut-off values: a single determination on day 14 or 15 is sufficient for a reliable prediction of pregnancy outcome. Eur J Obstet Gynecol Reprod Biol. 2006;127:94-8. PMID: 16466846 DOI: $10.1016 /$ j.ejogrb.2005.12.023

Lawler CC, Budrys NM, Rodgers AK, Holden A, Brzyski RG, Schenken RS. Serum beta human chorionic gonadotropin levels can inform outcome counseling after in vitro fertilization. Fertil Steril. 2011;96:505-7. PMID: 21719003 DOI: $10.1016 /$ j.fertnstert.2011.05.071

Lenton EA, Hooper M, King $\mathrm{H}$, Kumar A, Monks $\mathrm{N}$, Verma S, Osborn J. Normal and abnormal implantation in spontaneous in-vivo and in-vitro human pregnancies. J Reprod Fertil. 1991;92:555-65. PMID: 1886109 DOI: 10.1530/jrf.0.0920555

Liu HC, Kreiner D, Muasher SJ, Jones G, Jones H Jr, Rosenwaks $Z$. Beta-human chorionic gonadotropin as a monitor of pregnancy outcome in in vitro fertilization-embryo transfer patients. Fertil Steril. 1988;50:89-94. PMID: 3384122 DOI: $10.1016 / S 0015-0282(16) 60014-6$

Makrigiannakis A, Vrekoussis T, Zoumakis E, Kalantaridou SN, Jeschke U. The Role of HCG in Implantation: A Mini-Review of Molecular and Clinical Evidence. Int J Mol Sci. 2017;18:1305. PMID: 28629172 DOI: 10.3390/ ijms18061305

Papageorgiou TC, Leondires MP, Miller BT, Chang AS, Armstrong $A B$, Scott LA, Segars JH. Human chorionic gonadotropin levels after blastocyst transfer are highly predictive of pregnancy outcome. Fertil Steril. 2001;76:981-7. PMID: 11704121 DOI: $10.1016 /$ S0015-0282(01)02840-0

Poikkeus P, Hiilesmaa V, Tiitinen A. Serum HCG 12 days after embryo transfer in predicting pregnancy outcome. Hum Reprod. 2002;17:1901-5. PMID: 12093858 DOI: 10.1093/ humrep/17.7.1901

Porat S, Savchev S, Bdolah Y, Hurwitz A, Haimov-Kochman R. Early serum beta-human chorionic gonadotropin in pregnancies after in vitro fertilization: contribution of treatment variables and prediction of long-term pregnancy outcome. Fertil Steril. 2007;88:82-9. PMID: 17307176 DOI: $10.1016 /$ j.fertnstert.2006.11.116

Qasim SM, Callan C, Choe JK. The predictive value of an initial serum beta human chorionic gonadotropin level for pregnancy outcome following in vitro fertilization. J Assist Reprod Genet. 1996;13:705-8. PMID: 8947817 DOI: 10.1007/BF02066422 
Reljič M, Knez J, Vlaisavljević V. Human chorionic gonadotropin levels are equally predictive for pregnancy outcome after fresh and vitrified-warmed blastocyst transfer. J Assist Reprod Genet. 2013;30:1459-63. PMID: 24043384 DOI: $10.1007 / \mathrm{s} 10815-013-0099-6$

Schmidt LL, Asch RH, Frederick JL, Rojas FJ, Stone SC, Balmaceda JP. The predictive value of a single beta human chorionic gonadotropin in pregnancies achieved by assisted reproductive technology. Fertil Steril. 1994;62:333-8. PMID: 8034081 DOI: 10.1016/S0015-0282(16)56887-3

Shamonki MI, Frattarelli JL, Bergh PA, Scott RT. Logarithmic curves depicting initial level and rise of serum beta human chorionic gonadotropin and live delivery outcomes with in vitro fertilization: an analysis of 6021 pregnancies. Fertil Steril. 2009;91:1760-4. PMID: 18455162 DOI: 10.1016/j.fertnstert.2008.02.171

Stone BA, Vargyas JM, Ringler GE, March CM, Marrs RP. The rate at which serum total beta-subunit human chorionic gonadotropin increases after embryo transfer is a predictor of the viability of pregnancy and an identifier of determinants of pregnancy. Fertil Steril. 2006;86:1626-33. PMID: 17081527 DOI: 10.1016/j.fertnstert.2006.04.048

Sugantha SE, Webster S, Sundar E, Lenton EA. Predictive value of plasma human chorionic gonadotrophin following assisted conception treatment. Hum Reprod. 2000;15:46973. PMID: 10655325 DOI: 10.1093/humrep/15.2.469
Sung N, Kwak-Kim J, Koo HS, Yang KM. Serum hCG- $\beta$ levels of postovulatory day 12 and 14 with the sequential application of hCG- $\beta$ fold change significantly increased predictability of pregnancy outcome after IVF-ET cycle. J Assist Reprod Genet. 2016;33:1185-94. PMID: 27262839 DOI: $10.1007 / \mathrm{s} 10815-016-0744-y$

Tanbo TG, Zucknick M, Eskild A. Maternal concentrations of human chorionic gonadotrophin in very early IVF pregnancies and duration of pregnancy: a follow-up study. Reprod Biomed Online. 2018;37:208-15. PMID: 29773310 DOI: 10.1016/j.rbmo.2018.04.048

Tomic V, Kasum M, Vucic K. The role of luteal support during IVF: a qualitative systematic review. Gynecol Endocrinol. 2019;35:829-34. PMID: 31032676 DOI: $10.1080 / 09513590.2019 .1603288$

Trevethan R. Sensitivity, Specificity, and Predictive Values: Foundations, Pliabilities, and Pitfalls in Research and Practice. Front Public Health. 2017;5:307. PMID: 29209603 DOI: $10.3389 /$ fpubh.2017.00307

Urbancsek J, Hauzman E, Fedorcsák $P$, Halmos A, Dévényi $N$, Papp Z. Serum human chorionic gonadotropin measurements may predict pregnancy outcome and multiple gestation after in vitro fertilization. Fertil Steril. 2002;78:540-2. PMID: 12215330 DOI: 10.1016/S00150282(02)03278-8 